\title{
PREDICTING USER INTENTIONS FOR MOBILE LEARNING IN A PROJECT-BASED ENVIRONMENT
}

\author{
Ronnie Cheung \\ University of South Australia \\ City West Campus, 70, North Terrace, Adelaide SA 5000, Australia \\ ronnie.cheung@connect.polyu.hk
}

\begin{abstract}
This research investigates students' use of smartphones, and their attitudes toward the use of smartphones for learning. The research employs a quantitative approach. All respondents who participated in the study were selected from a degree course in marketing and public relations at the Hong Kong Polytechnic University. From the quantitative study, we collected 116 responses from a total of 140 students. Of the 116 students who responded to the survey, 105 students owned a smartphone. A regression analysis was performed to investigate the factors affecting smartphone usage for learning purposes. The research shows that learner aspects, online interactions, device features, and sharing are the main factors that affect mobile learning intentions in a project-based environment.
\end{abstract}

Keywords: Mobile, Project-Based, Learning, Smartphones

\section{INTRODUCTION}

This research investigates the impact of using mobile phones as the core information and communication technologies for teaching and learning at the Hong Kong Polytechnic University. Previous research ${ }^{1}$ reported that over 95 percent of students at the Hong Kong Polytechnic University are using Facebook for communications with mobile devices. Most of the mobile phones used by students are equipped with Internet access. The potential use of mobile phones integrated with a campus-wide wireless access network can facilitate the use of e-learning tools to enhance tutor-student and student-student communications. Student productivity will be enhanced by the provision of a ubiquitous computing environment. 
Researchers have implemented various examples of mobile learning using smartphones and hand-held laptop devices. A majority of research focuses on the implementation aspects of mobile learning. However, these studies fail to address the social aspects, special needs and motivations associated with learning in a mobile networking environment. The technological development of smart features accessible on smartphones allows students to access course Web pages anytime and anywhere. With the rapid development of Web $2.0^{2,3}$ technologies and smart mobile devices, technology implementation within a social context brings challenges that are hard to anticipate or predict how the technologies will be accepted and used. Focusing on daily activities for which students use their smartphones, this study investigates the key factors in integrating smartphones to support mobile learning for a project-based course delivered at the Hong Kong Polytechnic University.

In this study, we employ a frame model ${ }^{4}$ to investigate the major factors that affect student learning using mobile devices by investigating those factors that influence intentions to use smartphones for learning during the delivery of a course. In addition, the intentions for sharing experiences within the members in a project group are also considered in the research model.

\section{BACKGROUND OF THE STUDY}

This study investigates the use of mobile communications for teaching and learning in education. The use of smartphones for learning is evaluated in an undergraduate course for project-based learning at the Hong Kong Polytechnic University. In order to avoid overgeneralizations, this research focuses on the factors that influence the use of new technologies in the undergraduate-Advanced Marketing Research Project (AMR). In this project, groups of five to six students worked for selected companies. The continuous assessment consisted of five project-based assignments.

In this study, we introduced a project Web site for supporting communications and sharing among students in the AMR course. The assessment components included participation in Web-based activities and sharing of information on project work. Using the project Web site, students communicated collaboratively through a Web-based platform for problem formulation, literature review, research design, data analysis, and reporting. To cope with frequent communications for project-based collaborative activities, students were required to access the project Web site among peer members for exchange of ideas, files, and information. 
Figure 1 shows the details of a project Web site for supporting the advanced marketing research projects. Although the project Web site was designed for Web access among project group students through standard Web browsers on a personal computer, the use of the Google Technology platform also enables the Web site contents to be accessible through a mobile interface on smartphones. The various features of the project Web site can be accessed through the mobile interface through the menu bar on the left side of the screen (see Figure 1). The features of the Web-based platform to support learning include a Wiki page for supporting project definition, project discussions, file updates, benchmark dates, survey form, and time trackers. The front page of the project Web site also shows various levels of activities within a project group, highlighting recent updates, shared resources, comments, and activities within a project group. The development of the computer-mediated environment was based on a pedagogical approach that takes advantage of Web 2.0 affordances for knowledge sharing. In this example, students collaborated on a marketing research project relating to the tourism industry.

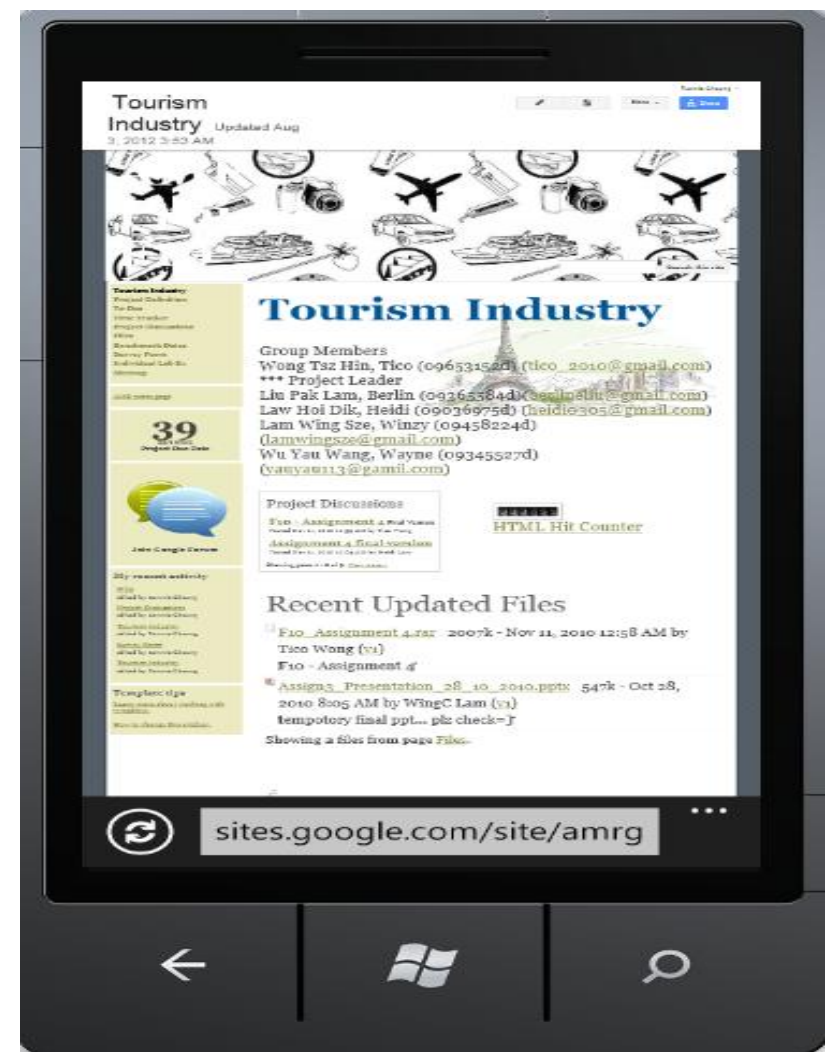

Figure 1. The project web site 
The Web 2.0 based supporting tools in the project Web site facilitated learners with diverse backgrounds and different levels of expertise to reflect on their learning through the marketing research project. With project-based learning implemented in small teams, the Web-based platform allowed students to share ideas among the project team members. By employing a Google account for each student to access the Web-based platform, the access privilege of the project resources within a project group was limited to peer group members. An advantage offered by this design was that the success of individual work could be linked to the group collaborations for the project. Furthermore, the activity log available from Google Applications also showed the contribution of all group members, allowing the instructor to assess the quality and quantity of contributions from different project team members.

Although these technologies are readily available and accessible to learners, their availability for access through a mobile platform does not imply that these technologies will be adopted by students. Levy and Kennedy ${ }^{5}$ point out that the widespread acceptance of communication technologies in non-teaching contexts does not necessarily mean that they can be effectively employed in educational contexts. There are other factors which might affect students' intentions to adopt a mobile technology for learning related to project-based activities. These include technological factors which are imposed by the capabilities of the mobile devices and social factors such as the influence of reference group members who are involved in working collaboratively on the marketing research project.

Although the collaborative aspects of project-based activities require students to communicate and interact frequently through computer-mediated environments, the computing facilities offered by mobile devices are not designed for use in a learning environment. The acceptance of a new technology takes time; not all learners might feel comfortable with using the new technology for learning. The technical limitations of the smart mobile devices include limited memory size, limited storage capacity, limited file transfer capability, limited screen size, and limited number of keypads and mouse functions available for efficient Web browsing. In addition, there are also difficulties associated with the input of text, particularly in English ${ }^{6}$.

Research has shown that students often use mobile phones for social networking and might not be willing to use them for other purposes, as these devices are dedicated to their own personal space. Therefore, ownership of smartphones cannot be assumed to lead directly to mobile learning without considering other factors. Furthermore, students' use of mobile devices for learning is affected by the influence of reference group members within their project group, who are collaborating frequently to accomplish 
project-based sharing activities. Teachers cannot assume that learning can be supported anytime, anywhere by smartphones simply on the premise that most students own smart mobile devices. Through a specific course implementation for project-based learning, this research investigates the factors which affect students' intentions to adopt smart mobile devices to support mobile learning with project-based activities. In particular, this project aims to achieve the following research objectives:

1. To study the behaviors and usage of smartphones among undergraduate students in Hong Kong; and

2. To investigate the factors that affect students' intentions to use smartphones to support learning for project-based learning activities.

\section{LITERATURE REVIEW}

Smart mobile phones are widely available to most people, and users are able to access Web sites and Internet services through mobile devices ${ }^{7}$. Such mobile technologies provide a means for learners to study anytime, anywhere. They offer the opportunities for learners to engage in more frequent and integral use of learning technologies at different locations, rather than through occasional use computing facilities through laboratories or desktop computers. Therefore, mobile learning through the use of smartphones has the potential to develop into the next generation learning environment and to facilitate more frequent interactions through mobile Web access. Researchers have investigated different factors that affect the use of smartphones for learning and argue that the adoption of the new technologies takes time. Moreover, there are psychological and technical factors that affect the adoption rate of these new technologies for learning ${ }^{8}$.

Nowadays, smartphones with mobile web access are becoming popular among students in Hong Kong. It allows people to access the relevant information and easily contact others. The Framework for the Rational Analysis of Mobile Education (FRAME) from Koole ${ }^{4}$ has been used to investigate factors that influence the use of smartphones for learning. The technical aspects of smartphones and the personal learning aspects of the learners are important factors that need to be considered for research in the mobile learning area. The frame model considers the technical factors of mobile devices as well as the social and personal aspects of learning. It describes the situation where the learner may participate in physical and virtual learning spaces and interact with peer group members by sharing information and resources anytime, anywhere.

Individual learners consume and create information daily for purposes relating to education. The interaction with information is usually mediated 
through technology. Through interaction, information becomes meaningful and useful. Within this context of information, the frame model is represented by a Venn diagram with the three aspects as shown in Figure 2: device aspects (D), learner aspects (L), and social aspects (S). The device aspect refers to the physical, technical, and functional characteristics of a mobile device. The learner aspect takes into account of an individual's cognitive abilities, memory, prior knowledge, emotions, and possible motivations. The social aspect takes into account the processes of social interaction and cooperation, including the reference group members within a project group.

The most important aspects for mobile learning are represented by three major aspects in terms of the intersecting elements. These intersecting elements are represented by device usability (DL), social technology (DS) and interactions (LS) that are supported by mobile learning. These three intersecting elements represent the affordance ${ }^{9}$ offered by the smartphone technology to support learning, which can be represented by the capabilities that an individual can potentially perform with the use of a technology. Finally, the three aspects that overlap in the center of Figure 2 represent the mobile learning situation for supporting project-based learning.

According to the research from Bradley and Holley ${ }^{2}$, the device aspect relates to the features available from the smartphones. Users of smartphones mainly focus on the size and resolution of the screen, Internet access ability, and other features such as Bluetooth, 3G, 4G, GPS and camera facilities. According to Clough, Jones, McAndrew, and Scanlon ${ }^{10}$, smartphone features affect students' intentions to use them for learning. At the same time, the number of students using their mobile phones to help with their learning increased from $12 \%$ in 2007 to $29 \%$ in 2009. Students often use smartphones to send emails and utilize instant messaging software to chat with other students when they have questions related to their studies.

The frame model is also suitable for investigating mobile learning intentions in the context of project-based learning. It highlights the role of technology as a kind of mediating artifact for supporting interactive learning activities. Furthermore, by considering the social aspects, it emphasizes the elements of learning through social processes. The elements of the frame model support the social learning model ${ }^{11}$, which is based on the premise that meaning is socially constructed through interactions with reference group members.

By engaging in mobile learning in project-based environments, students pursue solutions to marketing problems by working in groups to define approaches, debate ideas, make predictions, design plans and solutions, gather information, collect and analyze data, draw conclusions, 
and communicate their ideas and findings to others ${ }^{12}$. Through the project-based learning environment, students are presented with opportunities to engage in social learning with peer project group members through the social process of knowledge construction by making use of the Web-based platform that is accessible through smart mobile devices.

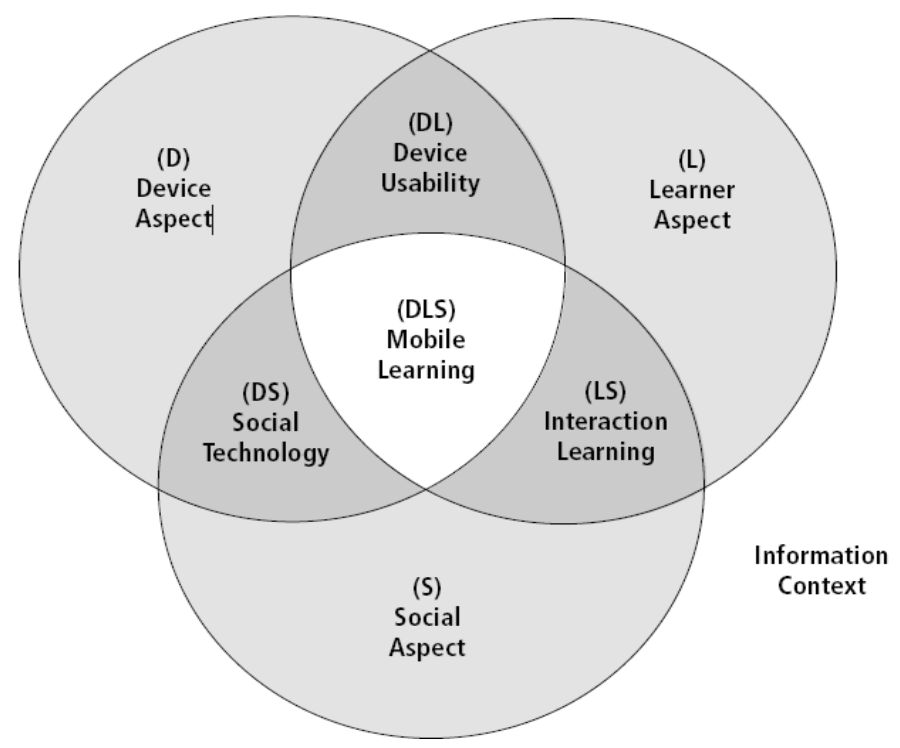

Figure 2. The frame model

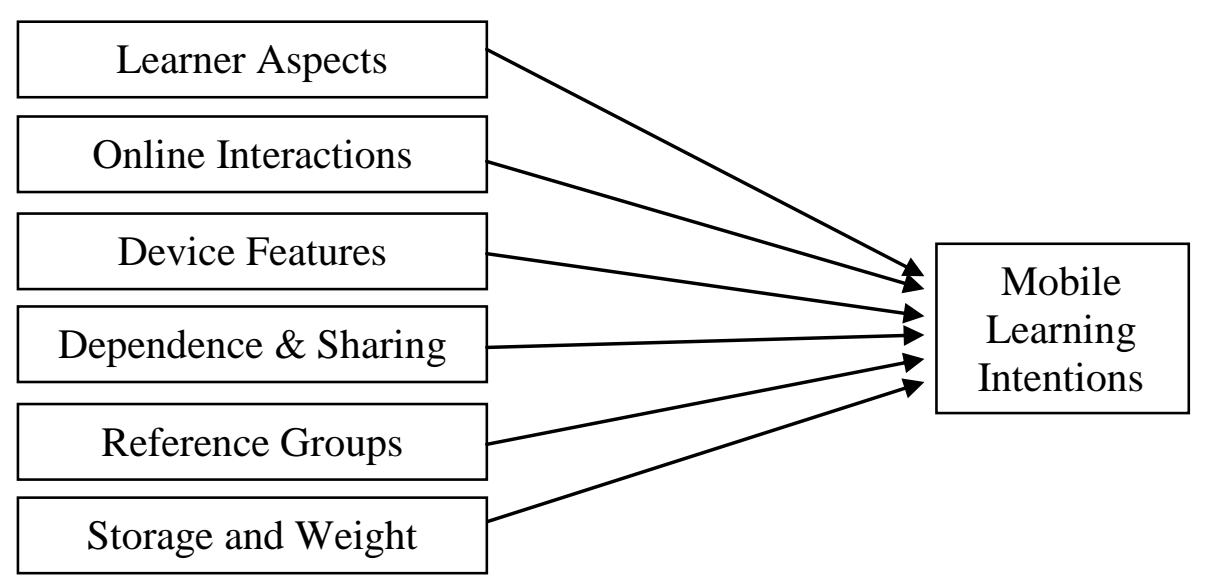

Figure 3. The research framework 


\section{RESEARCH FRAMEWORK}

This research investigates the use of smart mobile phones for teaching and learning in a project-based environment. This research emphasizes students' mobile learning intentions, rather than merely replicating course contents in mobile platforms. By referring to the frame model from Koole ${ }^{4}$, the factors that affect intentions for mobile learning include learner aspects, online interactions, device features, dependence and sharing, reference group, and storage and weight. Based on the frame model, a research framework is developed to predict students' intentions for mobile learning (Figure 3).

\section{RESEARCH METHOD}

A survey was used to collect data from the Advanced Marketing Research course in the marketing and public relations undergraduate program at the Hong Kong Polytechnic University. Through the course, students experienced the implementation of the project Web sites through the use of mobile communication technologies for teaching and learning. Experiences and ideas on how students use their mobile phones for learning were also investigated. We developed Web-based materials involving specific tasks to support active learning in a mobile environment. After the implementation of mobile learning in the selected classes, a structured questionnaire was used to investigate the factors that affect mobile learning intentions. The items regarding the constructs were measured using a seven-point Likert scale, with answer choices ranging from 'strongly disagree' (1) to 'strongly agree' (7). Through the investigation of the factors, it is possible to develop a culture among students to promote active learning in terms of thinking, task-specific learning, community building, and transcendence. Teaching and learning take place anytime and anywhere ${ }^{13}$.

\section{DATA ANALYSIS}

A structured questionnaire was distributed to a class of students attending the advanced marketing research course in the marketing and public relations program. From the quantitative research, we collected 116 responses from a total 140 students. Of the 116 students who responded to the survey, 105 students have a smartphone. As shown in Figure 4, during the class lessons, 14.2\% of the students used SMS, 14\% used Facebook, $12.5 \%$ used online dictionaries, and $11.7 \%$ used the Internet. Moreover, $62.9 \%$ of the respondents used their smartphones for learning; $52.3 \%$ used their smartphones for learning one to two times each day (Figure 5). The results showed that students actively use their smartphones during class lessons, which have significant implications for learning. 


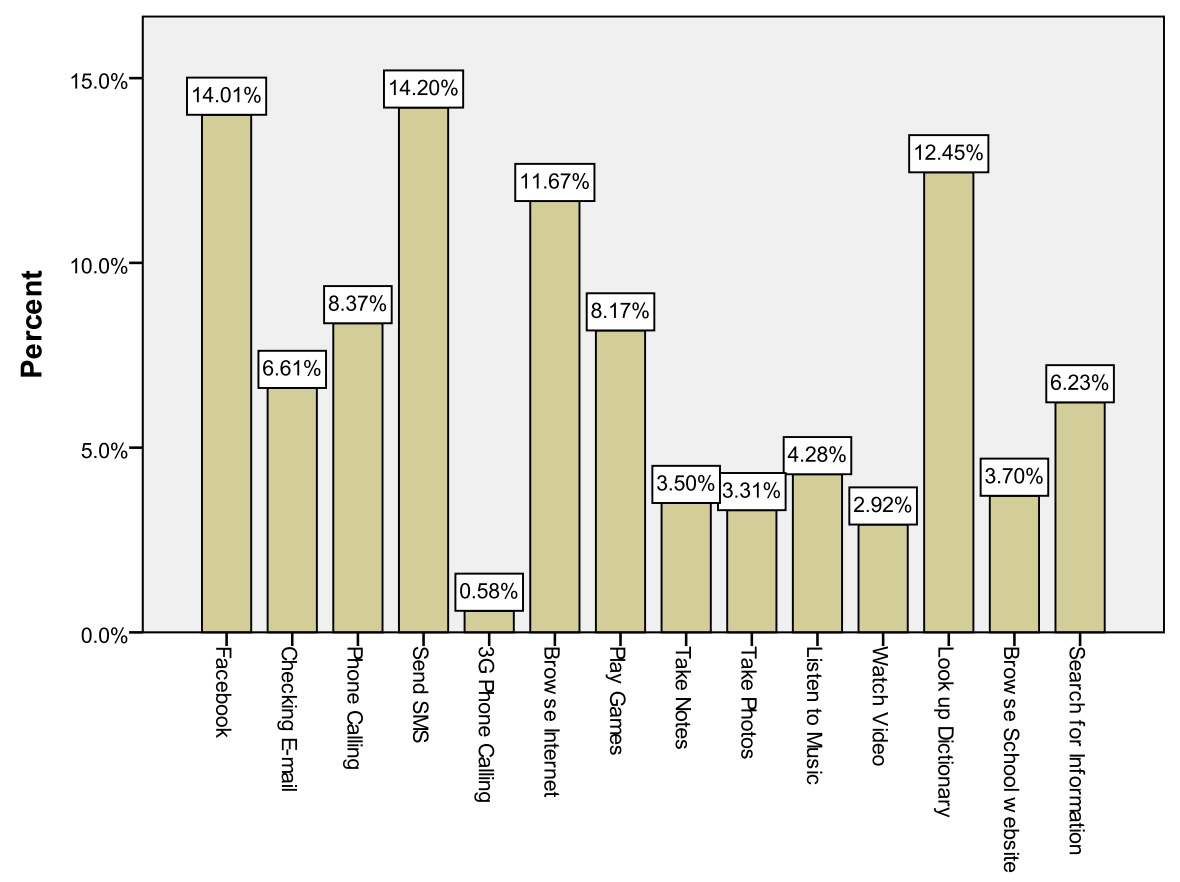

Smartphone Activities in Lessons

Figure 4. Activities during the class sessions

Considering that engagement in mobile learning was optional for students, the use of smartphones for learning was encouraging. The results of the usage analysis (as shown in Figure 5) show that half of the students were involved in mobile learning more than two times per day. As the survey was conducted with a class of students through project-based learning, the survey also covered the use of the Web-based platform for various project related activities. 


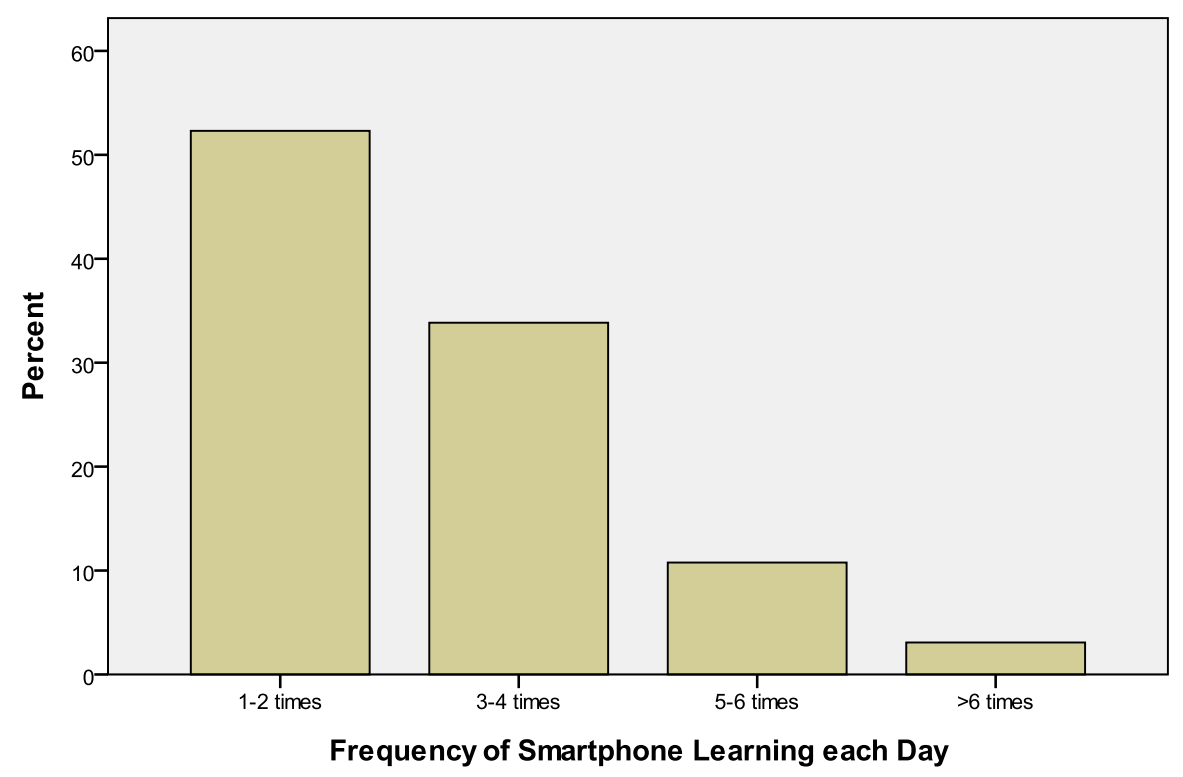

Figure 5. Frequencies of smartphone usage for learning

The project Web site shown in Figure 1 was developed to facilitate student's learning through project-based communications. In the learning platform, there were various facilities for students to communicate and work with group members, such as discussions in Google forums, uploading and downloading documents for sharing, Web site updates, and collaborative editing of Web pages. Students used a Gmail account to collaborate on their project activities through a project Web site. Teachers can also comment on students' project work through the Web site. Since project Web sites are normally not designed for mobile learning, we therefore collected feedback from students on Web access using smartphone for mobile learning. In order to understand whether students used their smartphone to access the project Web site facilities.

Figure 6 shows the various smartphone activities that are performed by students for project-based learning. By using the Web access facilities provided by smartphones, $10.1 \%$ of the students used Gmail, $10.1 \%$ of the students used the project Web site to read notes, project guidelines, and project samples. Through the mobile device, about $8 \%$ of the students read discussion forums messages, read sample papers, and downloaded notes. About $6.9 \%$ of students used Google scholar and downloaded files. On the project Web site, $6.88 \%$ of the students uploaded files using a mobile device, and $6.88 \%$ made comments on the project Web site. Note that only $5.5 \%$ of the students shared documents through their mobile devices, showing that 
students tend to use the mobile devices for reading and only occasionally for uploading contents.

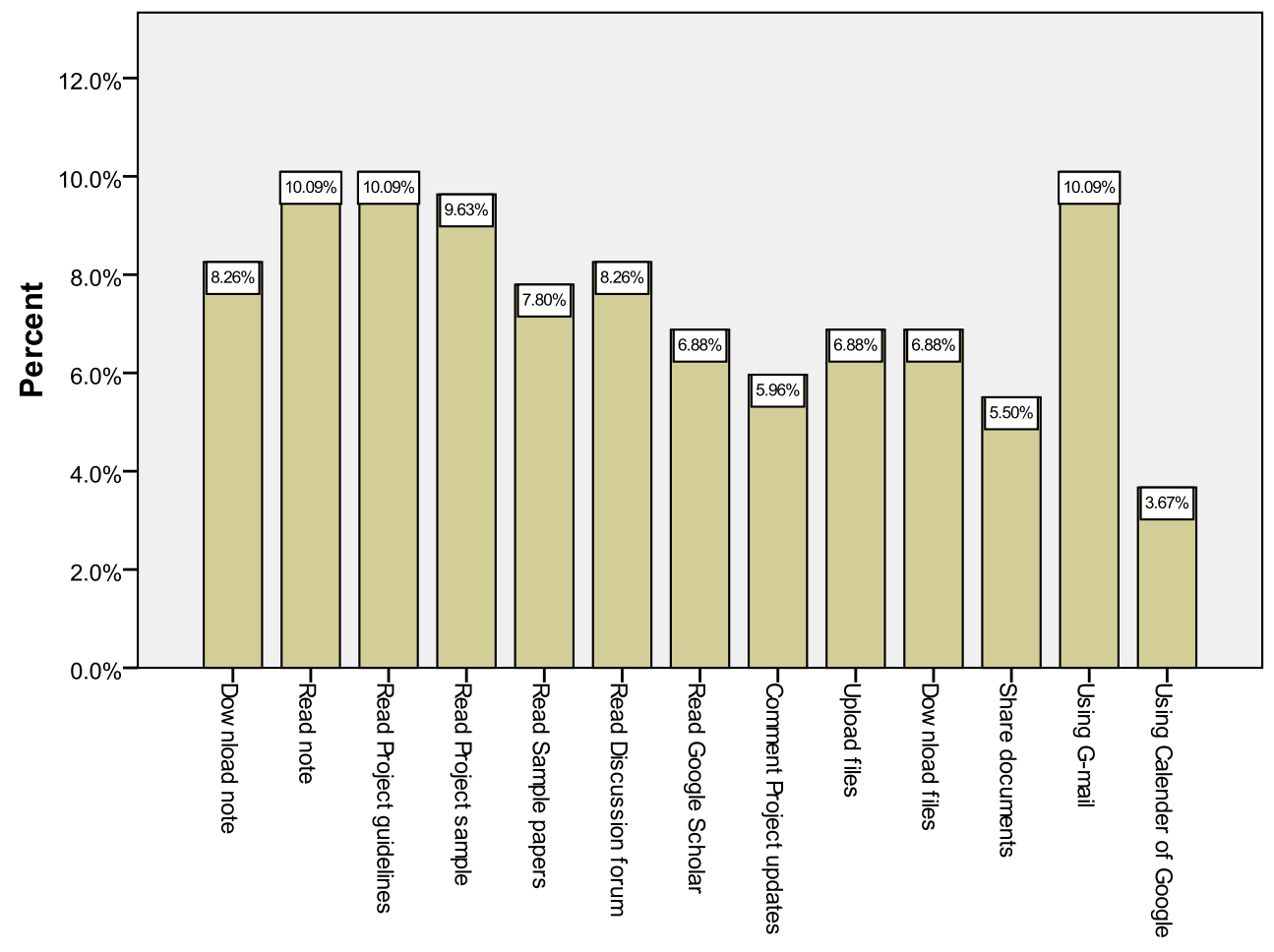

Smartphone Activities in AMR Google Platform

Figure 6. Smartphone activities for the project learning platform

\subsection{Reliability Analysis}

A reliability analysis was conducted for the six constructs used in this study (i.e. learner aspects, online interactions, device features, dependence and sharing, reference groups, storage and weight). Reliability refers to the extent to which an instrument consistently measures the same construct. To improve the reliability, all constructs used in this study were measured using at least two questionnaire items. The reliability of all constructs was assessed by Cronbach's alpha. As shown in Table 1, the Cronbach's alpha for each construct range from 0.749 to 0.908 , which is well above the recommended value of $0.70^{14}$. Most of the constructs used in this research exhibit sufficient internal reliability. 
Table 1.Cronbach's alpha for the constructs

\begin{tabular}{cc}
\hline Construct & Cronbach's Alpha \\
\hline Learner Aspects & .908 \\
Online Interactions & .880 \\
Device Features & .855 \\
Dependence \& Sharing & .790 \\
Reference Groups & .750 \\
Storage and Weight & .749 \\
\hline
\end{tabular}

\subsection{Factor Analysis}

Factor analysis employing the principal component method with a Varimax rotation with Kaiser Normalization was used to extract independent variables from the items of the questionnaire into six components. Factor analysis was used to ensure that the questionnaire items actually corresponded to the constructs defined in the research framework. All factor loadings were greater than 0.5, and the 29 questionnaire items for the independent variables clearly converge into six factors. All the 29 questionnaire items that were expected to load together actually do so. As shown in Table 2, the questionnaire items developed from the frame model converge into six factors. The six components extracted from factor analysis are learner aspects, online interactions, device features, dependence and sharing, reference groups, storage and weight.

Table 2. Factor analysis

\begin{tabular}{|c|c|c|c|c|c|c|}
\hline & \multicolumn{6}{|c|}{ Component } \\
\hline & 1 & 2 & 3 & 4 & 5 & 6 \\
\hline Willingness to use smartphones for learning & .721 & & & & & \\
\hline Ability of smartphones for learning anytime anywhere & .782 & & & & & \\
\hline Ability of smartphones for solving academic issues & .766 & & & & & \\
\hline Attitude toward mobile learning & .801 & & & & & \\
\hline Benefits of using smartphones for academic studies & .795 & & & & & \\
\hline Affections towards using smartphones for learning & .737 & & & & & \\
\hline Others using smartphones for learning & & & & & .510 & \\
\hline Reference group influence for buying smartphones & & & & & .830 & \\
\hline Reference group influence for mobile learning & & & & & .695 & \\
\hline
\end{tabular}

Note: Extraction Method: Principal Component Analysis. Rotation Method: Varimax with Kaiser Normalization. 
Table 2. Factor analysis (Cont.)

\begin{tabular}{|c|c|c|c|c|c|c|}
\hline & \multicolumn{6}{|c|}{ Component } \\
\hline & 1 & 2 & 3 & 4 & 5 & 6 \\
\hline $\begin{array}{l}\text { Willingness to encourage others to engage in mobile } \\
\text { learning }\end{array}$ & & & & .580 & & \\
\hline Willingness in uploading \& sharing learning materials & & & & .693 & & \\
\hline Free software supported by the school & & & & .708 & & \\
\hline Dependence of using smartphones for learning & & & & .619 & & \\
\hline Importance of weight & & & & & & .530 \\
\hline Importance of internal memory & & & & & & .777 \\
\hline Importance of memory card & & & & & & .805 \\
\hline Importance of screen size & & & .789 & & & \\
\hline Importance of battery power & & & .738 & & & \\
\hline Importance of input methods & & & .751 & & & \\
\hline Importance of operational speed & & & .816 & & & \\
\hline Importance of application software & & & .744 & & & \\
\hline Importance of data plan & & & .565 & & & \\
\hline Influence of teachers' online comments & & .614 & & & & \\
\hline Influence of online academic results & & .646 & & & & \\
\hline Influence of online learning materials & & .760 & & & & \\
\hline Influence of online submission of assignments & & .838 & & & & \\
\hline Influence of frequency of online submission & & .840 & & & & \\
\hline Influence of online comments from classmates & & .607 & & & & \\
\hline Influence of online project discussions & & .626 & & & & \\
\hline
\end{tabular}

Note: Extraction Method: Principal Component Analysis. Rotation Method: Varimax with Kaiser Normalization.

\subsection{Regression Analysis}

Based on the research framework, hypotheses were developed to investigate the factors that affect mobile learning intentions. The six factors that are considered to influence mobile learning intentions are: (1) learner aspects, (2) online interactions, (3) device features, (4) dependence and sharing, (5) reference groups, and (6) storage and weight. These six factors lead to the following hypotheses:

H1: Learner aspects positively influence mobile learning intentions.

H2: Online interactions positively influence mobile learning intentions.

H3: Device features positively influence mobile learning intentions. 
H4: Dependence and sharing positively influence mobile learning intentions.

H5: Reference groups positively influence mobile learning intentions.

H6: Storage and weight positively influence mobile learning intentions.

Table 3. Model summary

\begin{tabular}{ccccc}
\hline Model & $\mathrm{R}$ & R Square & $\begin{array}{c}\text { Adjusted R } \\
\text { Square }\end{array}$ & $\begin{array}{c}\text { Std. Error of } \\
\text { the Estimate }\end{array}$ \\
\hline 1 & $.635^{\mathrm{a}}$ & .404 & .367 & .741
\end{tabular}

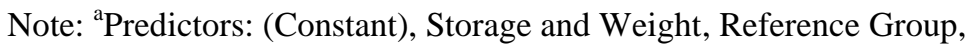
Dependence and Sharing, Device Features, Online Interactions, Learner Aspect; Dependent Variable: Mobile Learning Intention

Table 4. Coefficients ${ }^{\mathrm{a}}$

\begin{tabular}{|c|c|c|c|c|c|c|}
\hline \multirow{2}{*}{\multicolumn{2}{|c|}{ Model }} & \multicolumn{2}{|c|}{$\begin{array}{l}\text { Unstandardized } \\
\text { Coefficients }\end{array}$} & \multirow{2}{*}{$\begin{array}{c}\text { Standardized } \\
\text { Coefficients } \\
\text { Beta }\end{array}$} & \multirow[b]{2}{*}{$\mathrm{t}$} & \multirow[b]{2}{*}{ Sig. } \\
\hline & & B & $\begin{array}{l}\text { Std. } \\
\text { Error }\end{array}$ & & & \\
\hline \multirow[t]{7}{*}{1} & (Constant) & 3.638 & .072 & & 50.303 & .000 \\
\hline & Learner Aspect & .398 & .073 & .427 & 5.473 & .000 \\
\hline & Online Interactions & .317 & .073 & .341 & 4.368 & .000 \\
\hline & Device Features & .254 & .073 & .272 & 3.491 & .001 \\
\hline & $\begin{array}{l}\text { Dependence and } \\
\text { Sharing }\end{array}$ & .142 & .073 & .153 & 1.960 & .050 \\
\hline & Reference Groups & .014 & .073 & .015 & .191 & .849 \\
\hline & $\begin{array}{l}\text { Storage and } \\
\text { Weight }\end{array}$ & .080 & .073 & .086 & 1.105 & .272 \\
\hline
\end{tabular}

Note: ${ }^{\mathrm{a}}$ Dependent Variable: Mobile Learning Intentions

A regression analysis was conducted to determine those factors that have significant influence on the dependent variable. By referring to the results of regression analysis listed in Table 3, hypotheses $\mathrm{H} 1, \mathrm{H} 2, \mathrm{H} 3, \mathrm{H} 4$, $\mathrm{H} 5$ and $\mathrm{H} 6$ are tested. The $\mathrm{R}$-squared value $\left(\mathrm{R}^{2}=0.404\right)$ meant that $40.4 \%$ variance in the dependent variable can be explained by the combined effect of the six independent variables. As shown in Table 4, the p-values corresponding to Learner Aspects, Online Interactions and Device Features are smaller than 0.001 ; therefore, hypotheses $\mathrm{H} 1, \mathrm{H} 2, \mathrm{H} 3$ are supported at 
0.001 significance level. The p-value corresponding to Dependence and Sharing is also smaller than 0.05 ; therefore, hypothesis $\mathrm{H} 4$ is supported at 0.05 significant level. The p-values corresponding to Reference Groups, Storage and Weight are all greater than 0.05; therefore, hypothesis H5 and hypothesis H6 are not supported.

\section{DISCUSSION}

The popularity of smart mobile devices with Internet access provides huge potentials for enhancing project-based learning. The research results show that reasonable participation of students in a project learning Web site, even though mobile learning was not stated as necessary for participating in the marketing research course. Therefore, the results reflect the growing trend of students using smartphones to support learning. There are four major factors that significantly affect mobile learning intentions in a project-based environment: learner aspects, online interactions, device features, and dependence and sharing.

In order to facilitate mobile learning, various aspects might be considered through the use of mobile devices in project-based learning environments:

Learner Aspects: They cover the willingness and positive attitude of the learner towards the use of smartphones for learning. They also include the ability of the learner to use mobile devices to resolve daily academic matters and to provide benefits in terms of learning anytime, anywhere.

Online Interactions: They cover the online discussion among project members within a project group. They also include comments about project work from peer members and teachers as well as the interaction facilities relating to project assignment submission, feedback, and teaching support.

Device Features: The features include screen size, battery power, input methods, operation speed, supporting application software, and the type of data plan that is being employed with the mobile device to support Internet access.

Dependence and Sharing: The issues that affect mobile learning intentions include the learning situation (which requires smartphones to support mobility), the support provided by the lecturer, and the attitude of the learner towards content sharing for project-based learning among peer members using mobile devices.

In this study, the use of mobile devices for learning was optional for students in the advanced marketing research course. The results show a reasonable participation among students in employing mobile facilities to support learning. It should be noted that access to the Web-based project 
platform was mainly through the use of desktop devices such as students' home PCs or the university's computing facilities. While there is potential for promoting the use of mobile devices in formal learning environments, shorter, less demanding tasks can readily be supported through mobile learning.

\section{CONCLUSIONS}

This study focuses on students' use of smartphones for learning. The research employs a quantitative approach. A structured questionnaire was used to investigate the factors that affect students' intentions to use mobile phones for learning. All respondents who participated in the study were selected from a degree course in marketing and public relations at the Hong Kong Polytechnic University. From the quantitative study, we collected 116 responses from a total of 140 students. Of the 116 students who responded to the survey, 105 students owned a smartphone. A regression analysis was performed to investigate the factors affecting smartphone use for project-based learning. The results of the study show that learner aspects, online interactions, device features, and sharing are the main factors that affect smartphone usage for learning. On the other hand, the amount of storage, the weight of the mobile devices, and the influence of the reference group do not show any significant relationships on mobile learning intentions.

\section{ACKNOWLEDGMENT}

The author would like to thank the University of South Australia for supporting this research.

\section{REFERENCES}

[1] R. Cheung and D. Vogel, Can Facebook enhance the communications between teachers and students? The International Journal of Learning, 17(11), p385-397, 2011.

[2] A.P. McAfee, Enterprise 2.0, the dawn of emergent collaboration. MIT Sloagn Management Review, 47(4), p21-28, 2006. http://dx.doi.org/10.1109/EMR.2006.261380.

[3] J. Dron and T. Anderson, Lost in social space: Information retrieval issues in Web 1.5'. Journal of Digital information, 10(2), 2009. Retrieved on October 11, 2012, from http://journals.tdl.org/jodi/article/viewArticle/443/280\%C3\%82\%C2\% A0. 
[4] M.L. Koole, A model for framing mobile learning. In M. Ally (Ed.), Mobile learning - Transforming the delivery of education and training (p25-44). Canada: AU Press, 2009.

[5] M. Levy and C. Kennedy, Learning Italian via mobile SMS. In A. Kukulska-Hulme and J. Traxler (Eds.), Mobile learning: A handbook for educators and traniers (p76-83). London: Taylor and Francis, 2005.

[6] P. Thornton and C. Houser, M-learning: Learning in transit. In P. Lewis (Ed.), The changing face of CALL: A Japanese perspective (p229-243). The Netherlands: Swets\& Zeitlinger, 2002.

[7] C. Bradley and D. Holley, An analysis of first-year business students' mobile phones and their use for learning. In L. Creanor, D. Hawkridge, $\mathrm{K}$. Ng, and F. Rennie(Eds), Proceedings of the 17th Association for Learning Technology Conference (p89-98). England, UK: University of Nottingham, 2010. Retrieved on October 11, 2012, from http://repository.alt.ac.uk/797.

[8] S. Wang and M. Higgins, Limitations of mobile phones learning. The JALT CALL Journal, 2(1), p3-11, 2006.

[9] J.J. Gibson, The theory of affordances. In R. Shaw and J. Bransford (Eds.), Perceiving, acting, and knowing: Toward an ecological psychology (p67-82). Hillsdale, NJ: Houghton-Mifflin, Erlbaum, 1977.

[10] G. Clough, A.C. Jones, P. McAndrew, and E. Scanlon, Informal learning with PDAs and smartphones. Journal of Computer Assisted Learning, 24(5), p359-371, 2010. http://dx.doi.org/10.1111/j.1365-2729.2007.00268.x.

[11] J.S. Brown and R.P. Adler. Open education, the long tail, and learning 2.0. Educause Review, 43(1), p16-20, 2008.

[12] P.C. Blumenfeld, E. Soloway, R.W. Marx, J.S., Krajcik, M. Guzdial, and A. Palincsar. Motivating project-based learning: Sustaining the doing, supporting the learning. Educational Psychologist, 26(3-4), p369-398, 1991. http://dx.doi.org/10.1080/00461520.1991.9653139.

[13] PolyU, Active classroom for the 21st century: Directions for learning and teaching in PolyU to prepare tomorrow's students to meet the challenges of a knowledge-based society, Activate, PolyU. Retrieved on October 11, 2012 from https://www2.polyu.edu.hk/ltc/active_classroom.pdf.

[14] C. Fornell and D.F. Larcker. Evaluating structural equation models with unobservable variables and measurement error. Journal of Marketing Research, 18(1), p39-47, 1981. http://dx.doi.org/10.2307/3151312. 
